\title{
Protein Kinase B (Akt) Promotes Pathological Angiogenesis in Murine Model of Oxygen-Induced Retinopathy
}

\author{
Peng Wang ${ }^{1}$, Xiao-Feng Tian ${ }^{1}$ Jun-Bo Rong ${ }^{1}$, Dan Liu ${ }^{1}$, Guo-Guo Yi ${ }^{1}$ and Qian Tan ${ }^{1}$ \\ ${ }^{1}$ Department of Ophthalmology, Xiangya Hospital, Central South University, Changsha, PR China
}

Received November 29, 2010; accepted March 29, 2011; published online April 21, 2011

\begin{abstract}
Akt, or protein kinase $\mathrm{B}$, is an important signaling molecule that modulates many cellular processes such as cell growth, survival, and metabolism. However, the vivo roles and effectors of Akt in retinal angiogenesis are not explicitly clear. We therefore detected the expression of Akt using Western blotting or RT-PCR technologies in an animal model of oxygen-induced retinopathy, and investigated the effects of recombinant Akt on inhibiting vessels loss and Akt inhibitor on suppressing experimental retinal neovascularization in this model. We showed that in the hyperoxic phase of oxygen-induced retinopathy, the expression of Akt was greatly suppressed. In the hypoxic phase, the expression of Akt was increased dramatically. No significant differences were found in normoxic groups. Compared with control groups, administration of the recombinant Akt in the first phase of retinopathy markedly reduced capillary-free areas, while the administration of the Akt inhibitor in the second phase of retinopathy significantly decreased retinal neovascularization but capillaryfree areas. These results indicate that Akt play a critical role in the pathological process (vessels loss and neovascularization) of mouse model of oxygen-induced retinopathy, which may provide a valubale therapeutic tool for ischemic-induced retinal diseases.
\end{abstract}

Key words: recombinant Akt, Akt inhibitor, retinal vessel loss, retinal neovascularization, oxygen-induced retinopathy

\section{Introduction}

Retinopathy of prematurity (ROP) is a vessel-proliferative disorder of the retina primarily affecting premature infants. New vessel formation in ROP causes preventable blindness in children and diabetic retinopathy causes visual loss with vitreous hemorrhage, retinal detachment, and neovascular glaucoma $[35,36]$. In the murine model, there are two phases in the ROP pathological process. In the first phase, hyperoxia induces cessation of normal vessel growth and regression of existing vessels, subsequently, causing obliteration of normal retinal vessels. VEGF is essential in the development of the normal retinal vasculature, but supplemental oxygen interferes with normal VEGF driven

Correspondence to: Qian Tan, Department of Ophthalmology, Xiangya Hospital, Central South University, Changsha, PR China, No 87 Xiangya Road, Changsha 410008, China.

E-mail: tanqianxy99@yahoo.com.cn vascular development. During this phase, hyperoxia suppresses VEGF expression, resulting in the loss of the physiological wave of VEGF anterior to the growing vascular front [41], hyperoxia-induced vaso-obliteration is caused by apoptosis of vascular endothelial cells and can be partially prevented by administration of exogenous VEGF or PIGF-1, a VEGFR-1 specific ligand [2, 42, 44]. Besides, IGF-1 is critical in the first phase of ROP. IGF-1 controls maximum VEGF activation of the Akt endothelial cell survival pathway and the loss of IGF-1 expression could cause ROP by preventing the normal survival of vascular endothelial cells [20]. In the second phase, along with hyperoxia-induced vessel loss and subsequent relative hypoxia, the overexpression of pro-angiogenic substances including VEGF, angiopoietin, NO, EPO, IGF-1, TNF, etc., causes the development of retinal neovascularization, which is thought to occur in response to ischemic and hypoxic insult [12], which leads to alterations in the existing vasculature and compensatory, albeit pathological, new capillary growth $[17,29]$. That is 
to say, the insufficient blood supply resulting from early vessel loss causes tissue ischemia and hypoxia, which determines the severity of subsequent pathological retinal vessel growth. As the basic treatment for retinal neovascularization, laser photocoagulation cannot prevent progression of this aberrant angiogenesis and usually causes inflammation and tissue destruction [4].

Akt, also named protein kinase $\mathrm{B}$, is activated by a number of growth factors and cytokines, and serves as a multifunctional regulator of cell biology, glucose metabolism and protein synthesis [13, 21, 22]. Furthermore, several lines of evidence suggest a link between Akt and neovascularization. Endothelial nitric oxide synthase (eNOS) is a known downstream target of Akt, which has recently been shown to phosphorylate eNOS, leading to persistent activation [31], and contribute to postnatal neovascularization [1, 37, 39]. Moreover, recent studies suggest that Akt is known to mediate hypoxia-induced expression of VEGF in vitro and in vivo [3, 32], and the VEGF-induced endothelial cell migration requires the activation of Akt [8]. Akt involved in antiapoptosis signaling and is sufficient to promote survival of endothelial cells [16]. Numerous studies have demonstrated in various cell types that constitutive activation of Akt signaling is sufficient to block cell death induced by a variety of apoptotic stimuli and that transduction of dominant-negative Akt inhibits growth factor induced cell survival $[11,14,15,50]$. On the whole, Akt kinases, as a "master switch", control essential cellular functions, including proliferation, apoptosis, metabolism, and transcription, and have been considered as promising targets for treatment of pathological angiogenesis such as cancer and ischemic injury [5].

In this study, we sought to detect the expressions of Akt in the animal model of oxygen-induced retinopathy, and to investigate the role of Akt on suppressing experimental vessel loss and retinal neovascularization in this model.

\section{Materials and Methods}

\section{Animal model of proliferative retinopathy}

We certify that all applicable institutional and governmental regulations concerning the ethical use of animals were followed during this research. A reproducible model of oxygen-induced retinal neovascularization has been described previously in detail [46]. Briefly, sevenday-old C57BL/6J (P7) mice (Laboratory Animal Center of Central South University) were exposed to $75 \% \pm 2 \%$ oxygen (hyperoxia) for 5 days with the nursing mothers and then returned to room air for 5 days, producing retinal ischemia and neovascularization by P17. Mice of the same strain and of the same age were kept in room air and used as normoxia controls.

\section{Western blot analysis}

The mouse retinas were collected and lysed in lysis buffer $(20 \mathrm{mM}$ Tris, pH 7.4; $150 \mathrm{mM} \mathrm{NaCl} ; 1 \mathrm{mM}$ ethylenediamine tetraacetic acid; $1 \mathrm{mM}$ orthovanadate; $1 \mathrm{mM}$ phenylmethylsulfonyl fluoride; $1 \mu \mathrm{g} / \mathrm{ml}$ leupeptin; $10 \mu \mathrm{g} /$ $\mathrm{ml}$ aprotinin) containing protease inhibitors (Boehringer, Mannheim, Germany). After homogenization and centrifugation, the supernatant was collected for total protein values. The amount of protein was determined with the BCA protein assay kit (Sigma-Aldrich Chemical Co., St Louis, MO, USA). The total protein ( $40 \mu \mathrm{g}$ per lane) from each sample was loaded on sodium dodecylsulfate-polyacrylamide gel electrophoresis (SDS-PAGE) using a 10\% Tris-glycine gel (Invitrogen, Paisley, UK) and transferred onto a PVDF membrane (Pierce Co, Rockford, USA) at $300 \mathrm{~mA}$ for $1 \mathrm{hr}$. Antibody reaction was performed after blocking of nonspecific binding sites with 5\% skim milk. The membrane was incubated with goat polyclonal anti-Akt antibody and anti-pAkt antibody (1:1000 dilution; Cell Signaling Technology Inc, Danvers, MA) overnight at $4^{\circ} \mathrm{C}$, followed by incubation with horseradish peroxidase-conjugated secondary antibody (goat anti-rabbit antibody; Bytime, Haimen, China) for $2 \mathrm{hr}$ at room temperature. Peroxidase activity on PVDF membranes was visualized on X-ray film by means of the ECL Western blotting detection system (Amersham Pharmacia Biotech, Piscataway, NJ, USA). Experiments were repeated 3 times.

\section{$R N A$ extraction and RT-PCR}

Eyeballs were enucleated from the mice at P17, and the retinas were separated from eyeballs. The whole RNA of murine retinas were isolated with TRIzol reagent (Invitrogen, Paisley, UK) according to the manufacturer's instructions. Each RNA extract $(2 \mathrm{mg})$ was reversetranscribed into cDNA using RevertAidTM First Strand cDNA Synthesis Kit (Mbi, Glen Burnie, MD, USA). PCR was performed in $50 \mu \mathrm{l}$ of a solution containing Taq DNA polymerase, dNTP, RT products, Akt primer and GAPDH primer. To amplify Akt in the murine retinas, the primer pair 5-TGGACTTCCGATCAGGCTCAC-3 (sense) and 5-GCC CTTGCCCAGTAGCTTCA-3 (antisense) were used to generate $125 \mathrm{bp}$ PCR product. The primer pair 5-AAGCCCAT CACCATCTTCCA-3 (sense) and 5-CCTGCTTCACCACC TTCTTG-3 (antisense) were designed to generate $580 \mathrm{bp}$ PCR product of murine GAPDH.

After pre-incubation for $5 \mathrm{~min}$ at $94^{\circ} \mathrm{C}, 35$ cycles of amplification $\left(94^{\circ} \mathrm{C}\right.$ for $30 \mathrm{sec}, 55^{\circ} \mathrm{C}$ for $30 \mathrm{sec}$, and $72^{\circ} \mathrm{C}$ for $30 \mathrm{sec}$ ) were performed. Amplified products were run in a $1.5 \%$ ethidium bromide agarose gel, band intensities were captured with a ChemiDoc system and LabWorks software (UVP, Upland, CA, USA), and values were transferred to an Excel spreadsheet for calculation of means and standard errors.

\section{Angiography with high-molecular-weight fluorescein- dextran}

Mice were deeply anesthetized by intraperitoneal pentobarbital sodium and sacrificed by intracardiac perfusion with PBS containing $1 \mathrm{ml}$ of $50 \mathrm{mg} / \mathrm{ml}$ FITC-dextran (molecular weight 2,000,000, Sigma-Aldrich Chemical Co. St Louis, MO, USA). Subsequently, the eyes were enucleated and fixed 
A
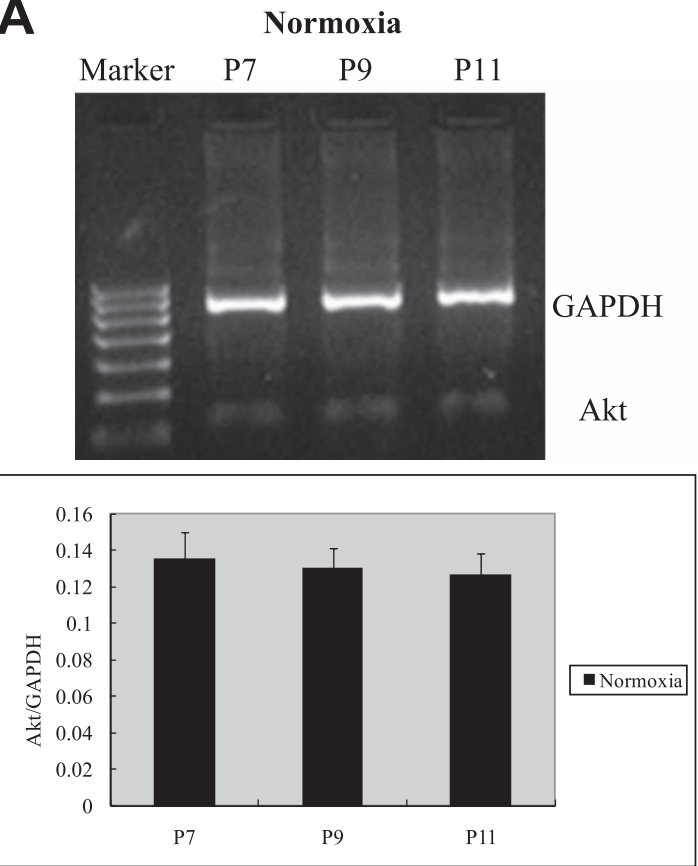

B
Marker P12 P14 P16
P17 P23
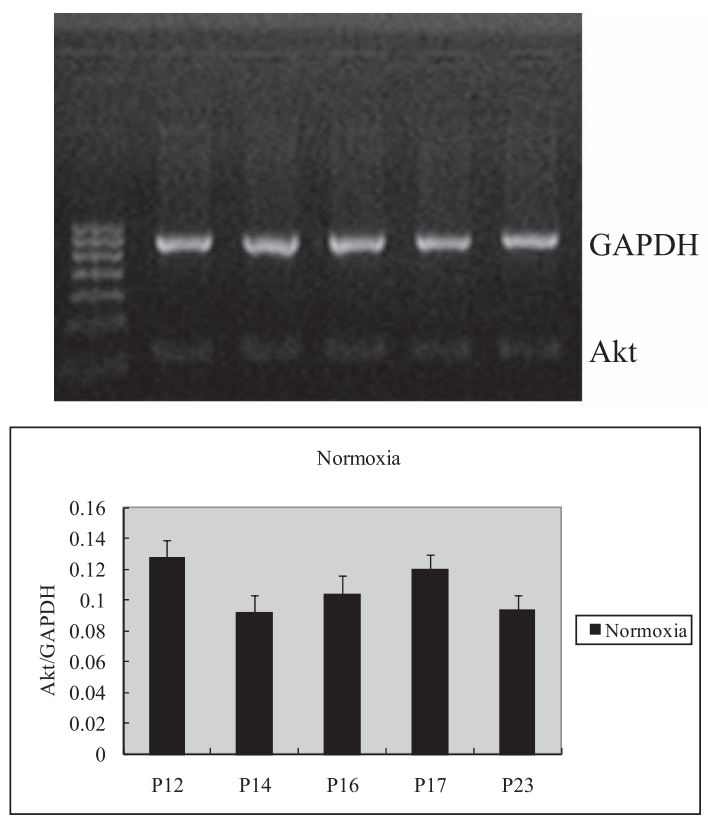
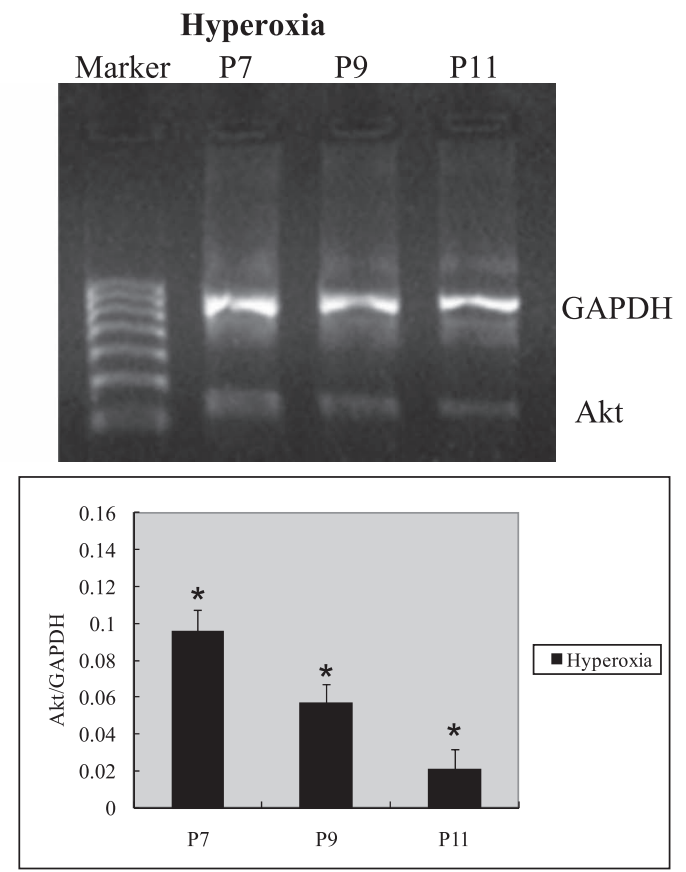

\section{Hypoxia}

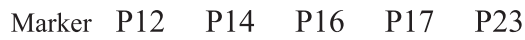
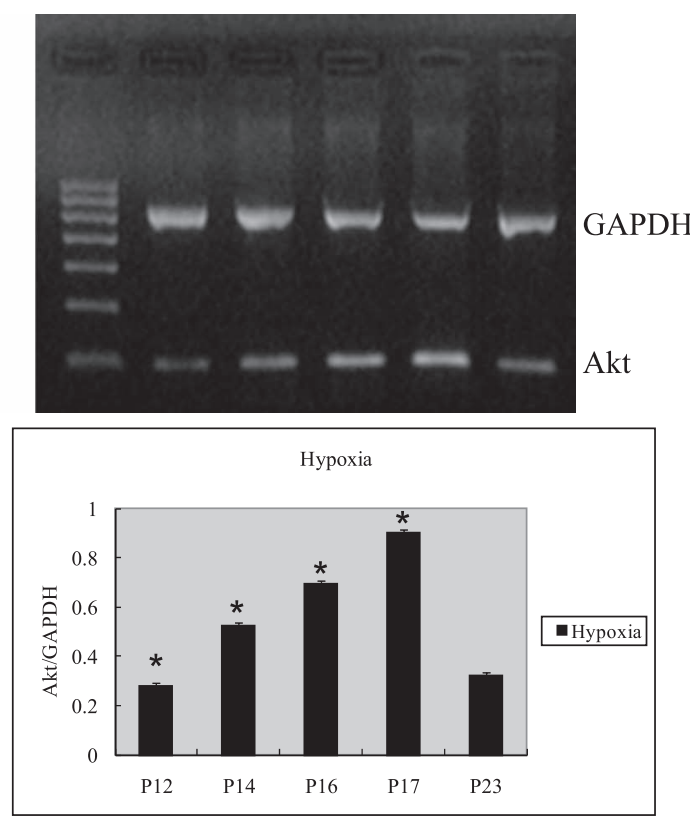

Fig. 1. RT-PCR and Western blot analysis for Akt or phosphorylated Akt in the retinas of experimental animals. The bands of mRNA or protein expression were measured by densitometry with Quantity One quantitation analysis software package. (A) The expression of Akt mRNA in the first phase (P7, P9, and P11) under normoxia or hyperoxia conditions and the relative Akt mRNA quantification related to GAPDH. Means \pm SEM of mRNA level normalized to GAPDH (internal control) were calculated. Statistical significance was determined by Student's t-test $\left({ }^{*} \mathrm{p}<0.05\right)$. (B) The expression of Akt mRNA in the second phase (P12, P14, P16, P17, P23) under normoxia or hypoxia conditions and the relative Akt mRNA quantification related to GAPDH. Means \pm SEM of mRNA level normalized to GAPDH (internal control) were calculated. Statistical significance was determined by Student's t-test $\left({ }^{*} \mathrm{p}<0.01\right)$. (C) The expression of Akt and p-Akt protein in the first phase (P7, P9, P11) under normoxia or hyperoxia conditions and the relative Akt or p-Akt protein quantification related to $\beta$-actin. Means \pm SEM of Akt or $\mathrm{p}$-Akt protein level normalized to $\beta$-actin (internal control) were calculated. Statistical significance was determined by Student's $t$ test $\left({ }^{*} p<0.01\right.$, $\left.{ }^{* *} \mathrm{p}<0.01\right)$. (D) The expression of Akt and p-Akt protein second phase (P12, P14, P16, P17, and P23) under normoxia or hypoxia conditions and the relative Akt or $\mathrm{p}$-Akt protein quantification related to $\beta$-actin. Means \pm SEM of Akt or p-Akt protein level normalized to $\beta$-actin (internal control) were calculated. Statistical significance was determined by Student's t test $\left({ }^{*} \mathrm{p}<0.05,{ }^{*} \mathrm{p}<0.05\right)$. 

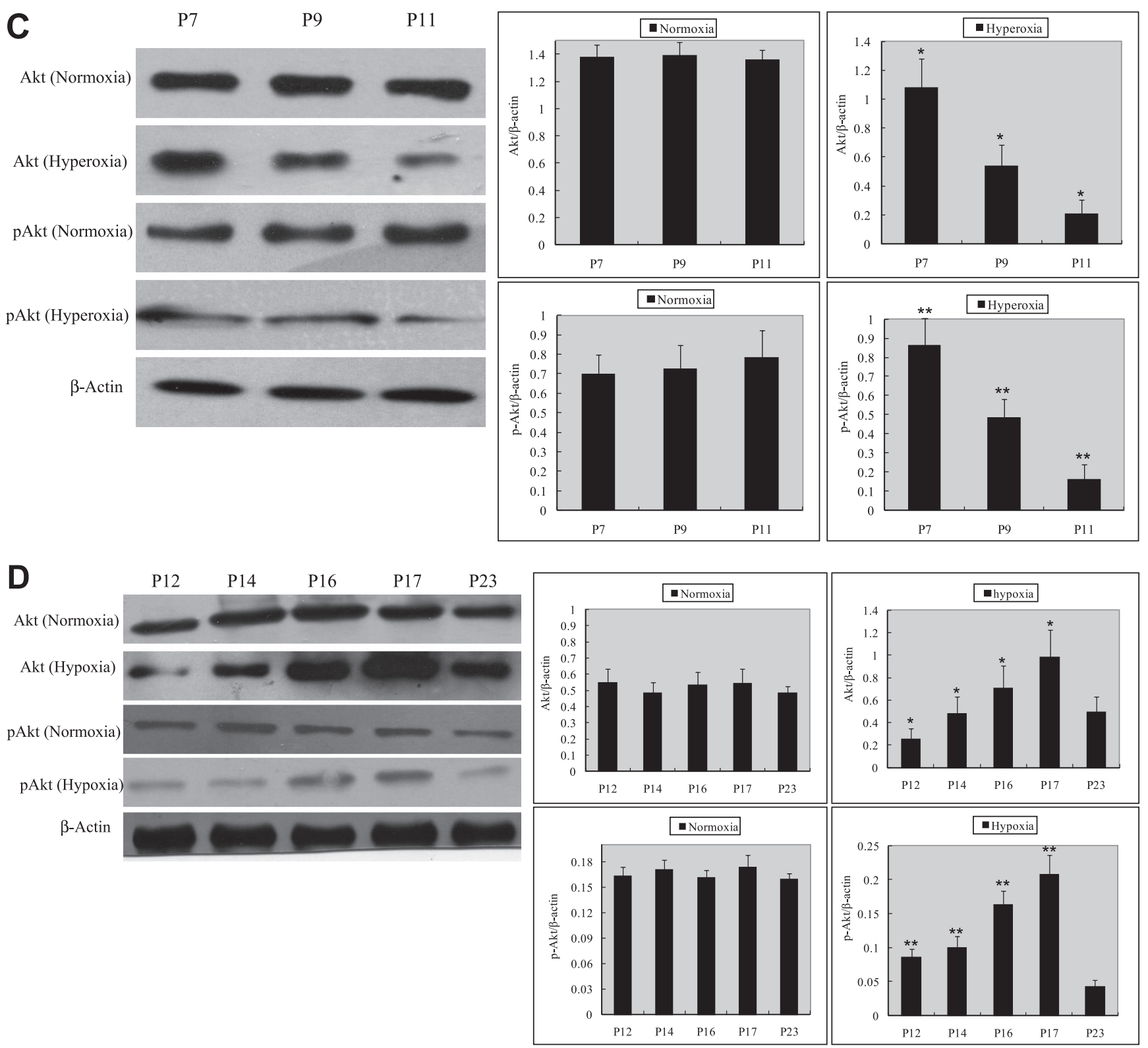

Fig. 1 (continued)

in $4 \%$ paraformaldehyde for $1 \mathrm{hr}$ at room temperature. The retinas were dissected and flat mounted on microscope slides with glycerol gelatin. Images of each of the 4 quadrants of whole mounted retina were taken at $\times 5$ magnifications on a Leica DMI 4000B confocal microscope (Wetzlar, Germany) and imported into Adobe Photoshop software. Retinal segments were merged to produce an image of the entire retina.

\section{Histologic quantitation of retinal neovascularization}

Mice were killed by IP injections of an overdose of sodium pentobarbital. Their eyes were enucleated, fixed with 4\% paraformaldehyde in PBS, and embedded in paraffin. A series of $6-\mu \mathrm{m}$ paraffin-embedded axial retinal sections were obtained starting at the optic nerve head and the sections were stained with hematoxylin and eosin. An individual blinded to the treatment groups examined the sections for evidence of neovascularization via light microscopy. Neovascularization was quantified by the number of retinal vascular endothelial cell nuclei anterior to the inner limiting membrane (ILM). Counts were performed in transverse sections through the center of the eye. Averaging of the 10 counted sections yielded a mean number of neovascular cell nuclei per section per eye [24, 48].

\section{Recombinant Akt and Akt inhibitor intravitreal injections}

For evaluation of vessel loss, at P6 and P7, mice were anesthetized with intraperitoneal injection of pentobarbital sodium. The lid fissure was opened using a Nol1 scalpel blade and the eye was proptosed. Intravitreal injections 
were performed by first entering the eye with an Ethicon TG140-8 suture needle at the posterior limbus. A 32-gauge Hamilton needle and syringe were used to deliver $1 \mu \mathrm{l}$ recombinant Akt (Abnova Taiwan Corporation, Taipei City, Taiwan) into the vitreous cavity. Control PBS was injected into littermates. The eye was then repositioned and the lids were approximated over the cornea. After oxygen exposure, eyes from P8 mice were perfused with FITC-dextran.

For evaluation of neovascularization, at P12, according to the same method, $1.5 \mu \mathrm{l} \mathrm{Akt}$ inhibitor (1L-6-hydroxymethyl-chiro-inositol2-(R)-2-O-methyl-3-Ooctadecylcarbonate. Merck Chemicals Ltd, Darmstadt, Germany) were injected into vitreous cavity. Control PBS was injected into littermates. Retinal neovascularization was analyzed with FITC-dextran and histological analysis at P17.

\section{Statistics}

The results were given as mean \pm SEM. One-way ANOVA followed by the LSD t-test was used to evaluate significant differences. A $p$ value $<0.05$ was considered statistically significant.

\section{Results}

\section{Akt mRNA expression and Akt, p-Akt protein expression during oxygen-induced retinopathy}

Retinal Akt mRNA, retinal Akt and p-Akt protein expression was greatly suppressed (Fig. 1A, C) during hyperoxia treatment (P7 to P12), when oxygen-induced retinal vessel loss occurs. After returning to room air, hypoxia induces retinal neovascularization (P12 to P17). During the relative hypoxic phase, retinal Akt mRNA, Akt and pAkt protein were increased dramatically (Fig. 1B, D). No significant differences were found in normoxia groups. These data suggest that lack of Akt in the first phase might contribute to early vessel loss and the onset of retinopathy, while the increase of Akt in the second phase might play a role in neovascularization.

\section{Use of exogenous Akt in the first phase can prevents retinal vessel loss}

We next examined whether exogenous Akt treatment during the first phase of oxygen-induced retinopathy (when retinal Akt levels are suppressed) helps to prevent retinal vessel loss. At P8, mice treated with recombinant Akt had a capillary-free/total retinal area of $13.0 \% \pm 0.8 \%$ compared with $31.4 \% \pm 0.3 \%$ in PBS-injected littermate controls $(\mathrm{P} \leq 0.001$; Fig. $2 \mathrm{~A}, \mathrm{~B})$, suggesting recombinant Akt treatment had a protective effect. These data demonstrate that correcting retinal Akt deficiency during the first phase of retinopathy with exogenous Akt protects the postnatal mouse retina from hyperoxia-induced vessel loss.

\section{Use of Akt inhibitor in the second phase can prevent retinal neovascularization, but cannot prevents retinal vessel loss}

In order to assess the role of Akt inhibitor function in retinal angiogenesis, we next explored whether late treatment with Akt inhibitor to prevent pathological angiogenesis in the second phase of retinopathy. Retinal neovascularization was also evaluated by measuring the neovascular
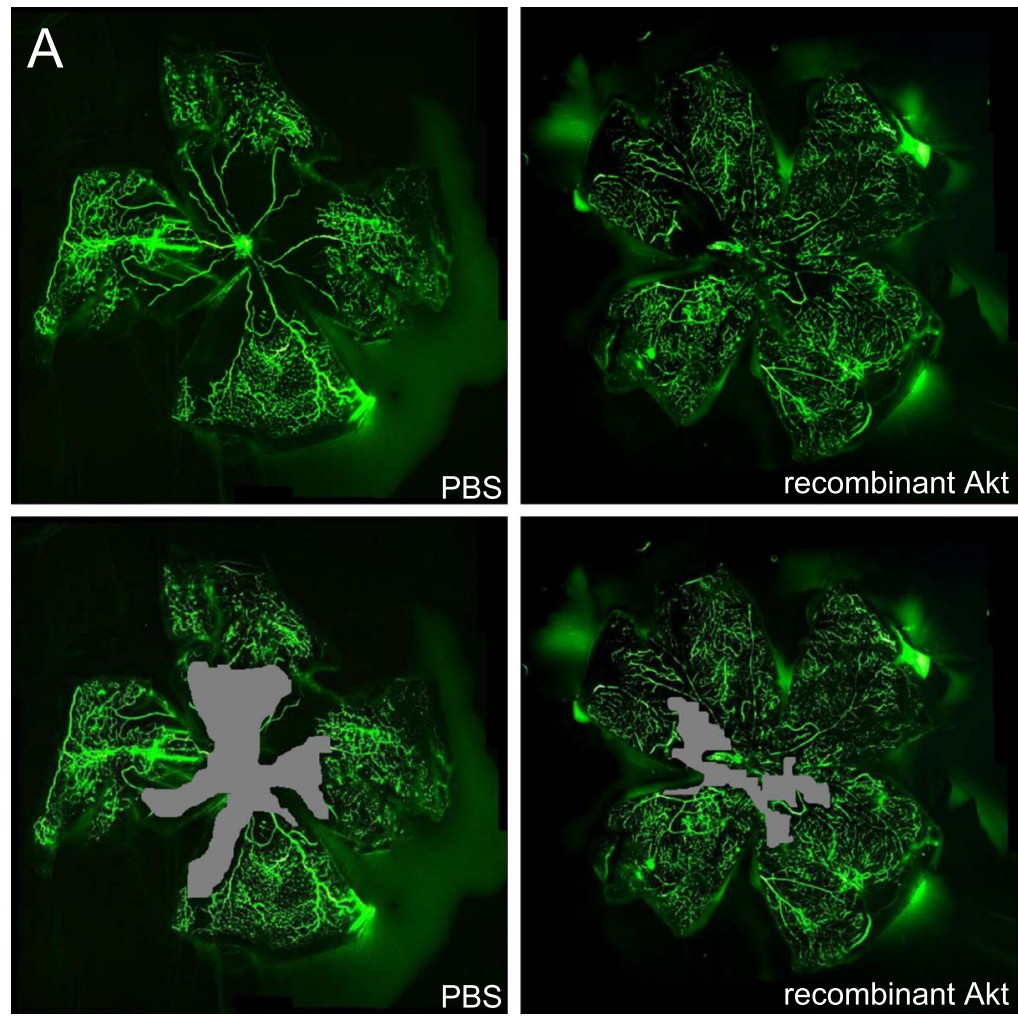

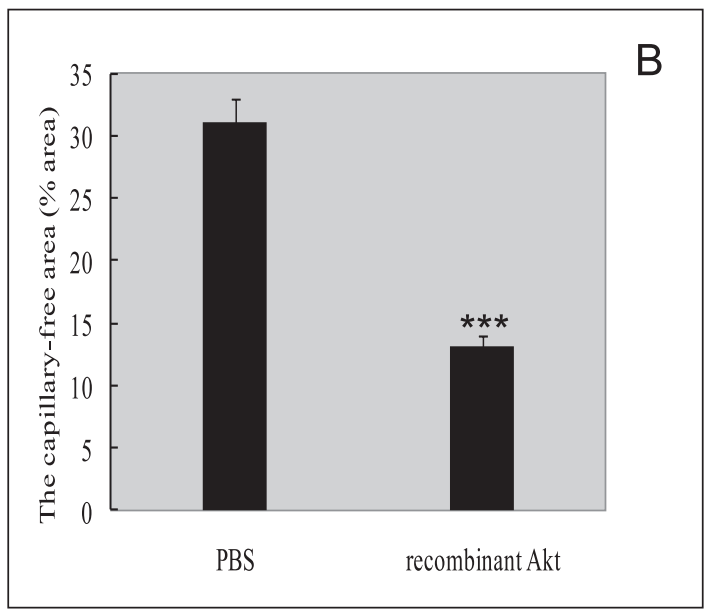

Fig. 2. Recombinant Akt treatment suppressed retinal vessel loss in a murine oxygen-induced retinopathy model. (A) Representative retinal whole-mounts showing area of capillary-free after $24 \mathrm{hr}$ of oxygen exposure and intraperitoneal injections (P6 and P7) of recombinant Akt and PBS. Areas of capillary (gray) were quantified. Original magnification $\times 5$. (B) The capillary-free areas and the total areas were quantified. Data are shown as mean \pm SEM. (PBS, $\mathrm{n}=10$; recombinant Akt, $\mathrm{n}=15 ; * * * \mathrm{P} \leq 0.001)$. 
tufts area and histological analysis. At P17, mice treated late with Akt inhibitor during the second phase had a pathologic neovascular tufts $(6.0 \% \pm 0.4 \%)$ compared with PBS control $(14.0 \% \pm 0.8 \%$; $\mathrm{P} \leq 0.001$; Fig. $3 \mathrm{~A}, \mathrm{~B})$. The histological analysis shows that the average numbers of neovascular cell nuclei were 51.0 \pm 5.0 in eyes injected with PBS $(n=10)$, and 17.0 \pm 3.0 in eyes injected with Akt inhibitor $(n=15)$. There was a significant reduction of neovascular nuclei following local delivery of Akt inhibitor in the mouse OIR model (Fig. 3D, E, P $\leq 0.001$ ). For the area of capillary-free, which was caused by centering on the optic nerve, no differences were seen in capillary-free area between Akt inhibitor and PBS treatments (Akt $21.3 \% \pm 0.5 \%$ compared with PBS $22.5 \% \pm 0.8 \%$ ). Our data suggest that Akt inhibitor treatment during the second phase of retinopathy protects the retina from vessel pathological proliferation, but cannot protect the retina from vessel loss.
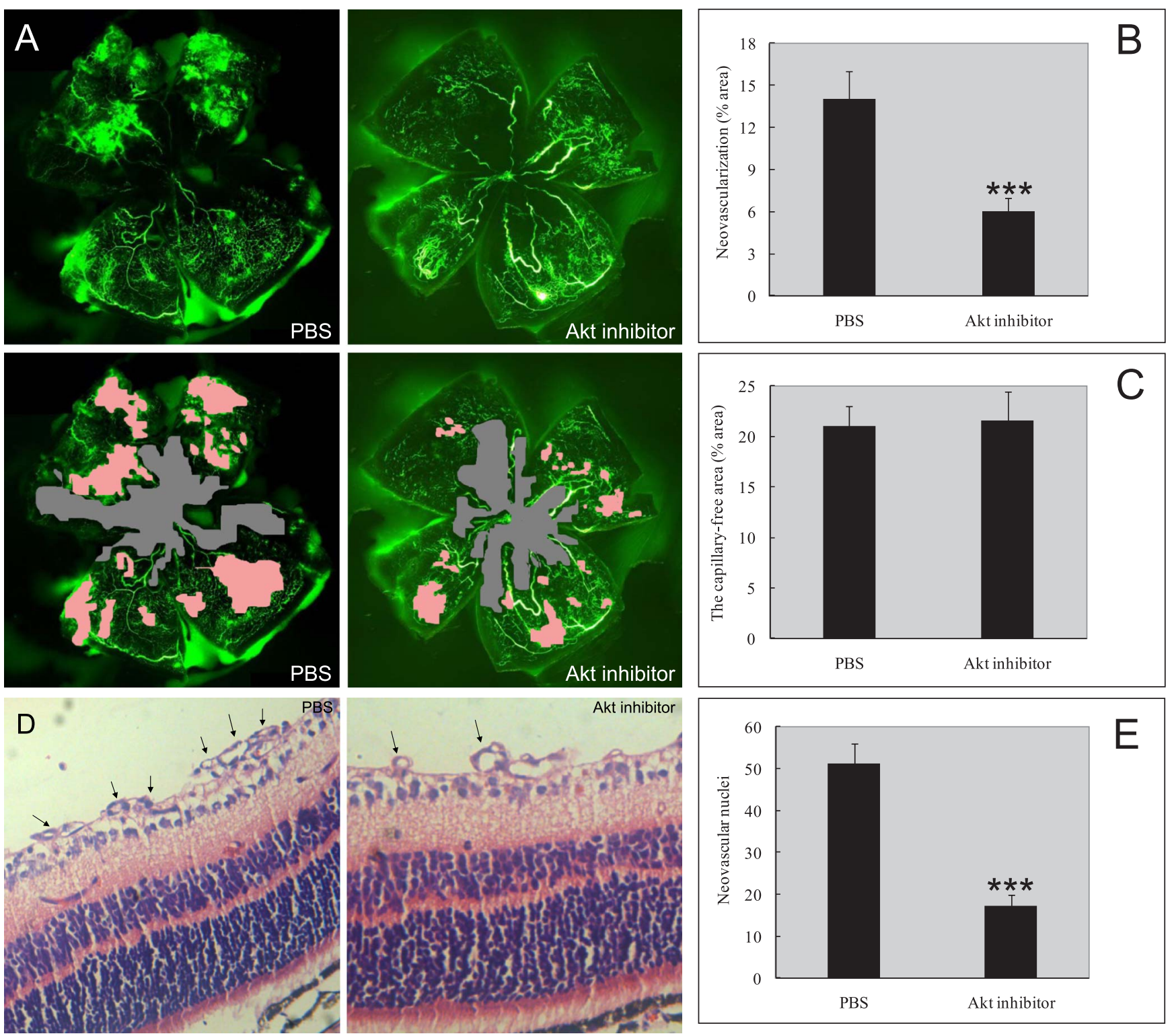

Fig. 3. Akt inhibitor treatment suppressed retinal neovascularization but not vessel loss in the murine oxygen-induced retinopathy model. (A) Representative retinal whole-mounts showing area of capillary-free and neovascularization after 5 days of relative oxygen deficiency exposure and intravitreal injections (P12) of Akt inhibitor and PBS. Areas of capillary (gray) and neovascularization (pink) were quantified. Original magnification $\times 5$. (B) The areas of neovascularization and the total areas were quantified. Data are shown as mean \pm SEM. (PBS, $n=10$; recombinant Akt, $\mathrm{n}=15 ;{ }^{* * *} \mathrm{P} \leq 0.001$ ). (C) The capillary-free areas and the total areas were quantified. (D) Histologic sections of $\mathrm{P} 17$ retina from PBS-treated (left) and Akt inhibitor-treated (right) eyes of mouse exposed to hyperoxia. Extensive preretinal neovascular tufts were apparent (arrow). (E) The number of neovascular nuclei anterior to the ILM in 6- $\mu \mathrm{m}$ retinal sections was quantified. (PBS, $\mathrm{n}=10$; recombinant Akt, $\mathrm{n}=15$; $* * * \mathrm{P} \leq 0.001)$ 


\section{Discussion}

The focus of the current study is to test the effects of Akt in preventing retinal vessel loss and neovascularization in vivo. Our results show that Akt presents a dynamic expression during the whole process of oxygen-induced retinopathy in the animal model. Early use of recombinant Akt can prevents retinal vessel loss and the late use of Akt inhibitor can apparently inhibits retinal neovascularization in mice.

In the first phase of oxygen-induced retinopathy, hyperoxia-induced vessel loss is caused by apoptosis of vascular endothelial cells, and also hyperoxia suppresses VEGF expression [32] and IGF-1 levels [20]. In our studies, we also found that Akt mRNA, Akt and p-Akt expression was greatly suppressed under hyperoxia environment. These data suggest that lack of Akt in the first phase might contribute to early vessel loss and the onset of retinopathy. In view of the antiapotosis effects of $\mathrm{Akt}$, we next treated model mouse with early use of recombinant Akt. It helps prevent the vessel loss and ischemia, thereby suppressing subsequent retinal neovascularization. Early use of Akt protects the retina from hyperoxia-induced vessel loss, which is consistent with previous studies that have found that activated Akt protects the lung from oxidant-induced injury and delays death of mice [30]. These findings suggest the important possibility of treating retinopathy patients early with Akt in order to prevent retinal ischemia without provoking neovascularization.

In addition, late inhibiting Akt alone during the neovascularization phase of retinopathy does protect retinal vasculature, and could decrease the formation of neovascularization dramatically, but the normal total retinal vascular area was not significantly changed. The second phase of ROP is characterized by hypoxia-induced retinal neovascularization. These leaky vessels can lead to retinal detachment and blindness. In this phase, we found that Akt mRNA, Akt and p-Akt expression are elevated, which contribute to pathological retinal angiogenesis. Administering Akt inhibitor to these patients could suppress the retinal neovascularization. Akt plays a very central role in promoting the survival of a wide range of cell types [50], and several studies indicate that Akt activation plays an important role in inhibiting cell apoptosis in fibroblasts, epithelial and lymphoid cell lines, and neuronal cells [28]. In ECs, the majority of growth factor-induced responses are mediated by the activation of the Akt signaling pathway [45]. Vascular endothelial growth factor (VEGF) displays multiple biological activities in endothelial cells, including the enhancement of retinal endothelial cell survival [2]. In addition, it was also shown that several other stimuli including insulin-like growth factor-I (IGF-I) [33], insulin [23], angiopoietin-1 (Ang-1) [40], hepatocyte growth factor [38], the small proteoglycan decorin [43], fluid shear stress [46], sphingosine-1-phosphate (S1P) [26], estrogen [34], reactive oxygen species [47], and corticosteroids [19] also activate Akt signaling, illustrating the central role of this pathway in controlling endothelial cell viability. Blocking of Akt pathway also can effectively inhibit retinal endothelial cell survival and migration induced by VEGF in vitro [49]. Moreover, shear stress and insulin could inhibit endothelial cell apoptosis by activating Akt $[6,23]$. Thus, activation of Akt seems to be a general antiapoptotic mechanism induced by proangiogenic stimuli. Because apoptosis of endothelial cells can against angiogenesis, we speculate that the Akt signaling pathway leading to apoptosis suppression may significantly contribute to angiogenesis, a process required for the revascularization of ischemic tissue. Akt signaling is important for normal vascular development, since depletion of Akt leads to angiogenic defects [5], Akt is expressed in the retina suggesting that it is an endogenous retinal survival factor, and that the Akt pathway can increase endothelial cell proliferation and protect vasculature counteract ischemia and apoptosis. Akt and p-Akt are present in retinal vessels. Therefore they may be activated locally to promote retinal cell survival.

Apart from the mature ECs, many studies have also been done on the regulation of the EPCs biology by Akt. The study by Grant et al. indicates that adult hematopoietic stem cells can clonally differentiate into all hematopoietic cell lineages as well as endothelial cells that revascularize the adult retina. They also show that recruitment of endothelial precursors to sites of ischemic injury has a significant role in retinal neovascularization [18]. Recent studies revealed that statins requires activation of the PI3K/Akt pathway to augment EPC differentiation and promote neovascularization, suggesting a common mechanism and an essential role for Akt in regulating hematopoietic stem cell differentiation [9, 10, 27]. Subsequently, it is not only demonstrated that Akt regulates differentiation of EPCs, but also considered that Akt can be used as a target to modify EPCs kinetics [7]. Furthermore, Akt can modulate the trafficking of EPCs in ischemic muscle [25], and Akt knockout mice have reduced EPCs mobilization in response to limb ischemia [1].

In summary, we have shown that recombinant Akt has potent inhibitory effects on the vessel loss and the subsequent development of retinal neovascularization, and that the Akt inhibitor has dramatic effects on inhibiting retinal neovascularization alone in vivo. Local treatment can produce less toxicity than systemic delivery, so we chosed to deliver recombinant Akt and Akt inhibitor via intravitreal injection in order to limit side effects that might appear after systemic delivery. We did not observe the toxicity of recombinant Akt and Akt inhibitor in this study. These data suggest that targeting Akt function could provide a novel approach for treatment of angiogenesis in retinal neovascularization diseases.

\section{Conflict of Interest}

The authors declare no conflict of interest. 


\section{References}

1. Ackah, E., Yu, J., Zoellner, S., Iwakiri, Y., Skurk, C., Shibata, R., Ouchi, N., Easton, R. M., Galasso, G., Birnbaum, M. J., Walsh, K. and Sessa, W. C. (2005) Akt1/protein kinase Balpha is critical for ischemic and VEGF-mediated angiogenesis. J. Clin. Invest. 115; 2119-2127.

2. Alon, T., Hemo, I., Itin, A., Pe'er, J., Stone, J. and Keshet, E. (1995) Vascular endothelial growth factor acts as a survival factor for newly formed retinal vessels and has implications for retinopathy of prematurity. Nat. Med. 1; 1024-1028.

3. Arsham, A. M., Plas, D. R., Thompson, C. B. and Simon, M. C. (2004) Akt and hypoxia-inducible factor-1 independently enhance tumor growth and angiogenesis. Cancer Res. 64; 35003507

4. Bandello, F., Brancato, R., Menchini, U., Virgili, G., Lanzetta, P., Ferrari, E. and Incorvaia, C. (2001) Light panretinal photocoagulation (LPRP) versus classic panretinal photocoagulation (CPRP) in proliferative diabetic retinopathy. Semin. Ophthalmol. $16 ; 12-18$

5. Chen, J., Somanath, P. R., Razorenova, O., Chen, W. S., Hay, N., Bornstein, P. and Byzova, T. V. (2005) Akt1 regulates pathological angiogenesis, vascular maturation and permeability in vivo. Nat. Med. 11; 1188-1196.

6. Dimmeler, S., Assmus, B., Hermann, C., Haendeler, J. and Zeiher, A. M. (1998) Fluid shear stress stimulates phosphorylation of $\mathrm{Akt}$ in human endothelial cells: involvement in suppression of apoptosis. Circ. Res. 83; 334-341.

7. Dimmeler, S., Fleming, I., Fisslthaler, B., Hermann, C., Busse, R and Zeiher, A. M. (1999) Activation of nitric oxide synthase in endothelial cells by Akt-dependent phosphorylation. Nature 399; 601-605

8. Dimmeler, S., Urbich, C. and Zeiher, A. M. (1999) Vascular endothelial growth factorinduced endothelial cell migration requires Akt-stimulated activation of endothelial nitric oxide-synthase. Circulation 100 (suppl I); I-483. Abstract 2543

9. Dimmeler, S. and Zeiher, A. M. (2000) Akt takes center stage in angiogenesis signaling. Circ. Res. 86; 4-5

10. Dimmeler, S., Aicher, A. and Vasa, M. (2001) HMG-CoA reductase inhibitors (statins) increase endothelial progenitor cells via the PI3K-kinase/Akt pathway. J. Clin. Invest. 108; 391-397.

11. Dudek, H., Datta, S. R., Franke, T. F., Birnbaum, M. J., Yao, R., Cooper, G. M., Segal, R. A., Kaplan, D. R. and Greenberg, M. E. (1997) Regulation of neuronal survival by the serine-threonine protein kinase Akt. Science 275; 661-665.

12. Frank, R. N. (1991) On the pathogenesis of diabetic retinopathy. A 1990 update. Ophthalmology 98; 586-593.

13. Franke, T. F., Yang, S. I., Chan, T. O., Datta, K., Kazlauskas, A., Morrison, D. K., Kaplan, D. R. and Tsichlis, P. N. (1995) The protein kinase encoded by the Akt proto-oncogene is a target of the PDGF activated phosphatidylinositol 3-kinase. Cell 81; 727736.

14. Fujio, Y., Guo, K., Mano, T., Mitsuuchi, Y., Testa, J. R. and Walsh, K. (1999) Cell cycle withdrawal promotes myogenic induction of Akt, a positive modulator of myocyte survival. Mol. Cell Biol. 19; 5073-5082.

15. Fujio, Y., Nguyen, T., Wencker, D., Kitsis, R. N. and Walsh, K. (2000) Akt promotes survival of cardiomyocytes in vitro and protects against ischemia reperfusion injury in mouse heart. Circulation 101; 660-667.

16. Gerber, H. P., McMurtrey, A., Kowalski, J., Yan, M., Keyt, B. A., Dixit, V. and Ferrara, N. (1998) Vascular endothelial growth factor regulates endothelial cell survival through the phosphatidylinositol 3'-kinase/Akt signal transduction pathway. Requirement for Flk-1/KDR activation. J. Biol. Chem. 273; 3033630343.

17. Grant, M. B., Russell, B., Fitzgerald, C. and Merimee, T. J.
(1986) Insulin-like growth factors in vitreous: studies in control and diabetic subjects with neovascularization. Diabetes 35; 416420 .

18. Grant, M. B., May, W. S. and Caballero, S. (2002) Adult hematopoietic stem cells provide functional hemangioblast activity during retinal neovascularization. Nat. Med. 8; 607-612.

19. Hafezi-Moghadam, A., Simoncini, T., Yang, E., Limbourg, F. P., Plumier, J. C., Rebsamen, M. C., Hsieh, C. M., Chui, D. S., Thomas, K. L., Prorock, A. J., Laubach, V. E., Moskowitz, M. A., French, B. A., Ley, K. and Liao, J. K. (2002) Acute cardiovascular protective effects of corticosteroids are mediated by non-transcriptional activation of endothelial nitric oxide synthase. Nat. Med. 8; 473-479.

20. Hemmings, B. A. (1997) Akt signaling: linking membrane events to life and death decisions. Science $275 ; 628-630$.

21. Hemmings, B. A. (1997) PH domains-a universal membrane adapter. Science 275; 1899.

22. Hemmings, B. A. (1997) PtdIns (3, 4, and 5) P3 gets its message across. Science 277; 534.

23. Hermann, C., Assmus, B., Urbich, C., Zeiher, A. M. and Dimmeler, S. (2000) Insulin-mediated stimulation of protein kinase Akt: a potent survival signaling cascade for endothelial cells. Arterioscler. Thromb. Vasc. Biol. 20; 402-409.

24. Hu, L., Hofmann, J. and Jaffe, R. B. (2005) Phosphatidylinositol 3-kinase mediates angiogenesis and vascularization permeability associated with ovarian carcinoma. Clin. Cancer Res. 11; 82088212.

25. Hur, J., Yoon, C. H., Lee, C. S., Kim, T. Y., Oh, I. Y., Park, K. W., Kim, J. H., Lee, H. S., Kang, H. J., Chae, I. H., Oh, B. H., Park, Y. B. and Kim, H. S. (2007) Akt is a key modulator of endothelial progenitor cell trafficking in ischemic muscle. Stem Cells 25; 1769-1778.

26. Igarashi, J., Bernier, S. G. and Michel, T. (2001) Sphingosine 1-phosphate and activation of endothelial nitric-oxide synthase. differential regulation of Akt and MAP kinase pathways by EDG and bradykinin receptors in vascular endothelial cells. J. Biol. Chem. 276; 12420-12426.

27. Kapur, R., Cooper, R., Zhang, L. and Williams, D. A. (2001) Cross-talk between alpha(4)beta(1)/alpha(5)beta(1) and c-Kit results in opposing effect on growth and survival of hematopoietic cells via the activation of focal adhesion kinase, mitogenactivated protein kinase, and Akt signaling pathways. Blood 97; 1975-1981.

28. Kennedy, S. G., Wagner, A. J., Conzen, S. D., Jordán, J., Bellacosa, A., Tsichlis, P. N. and Hay, N. (1997) The PI 3-kinase/ Akt signaling pathway delivers an anti-apoptotic signal. Genes Dev. 11; 701-713.

29. Limb, G. A., Chignell, A. H., Green, W., LeRoy, F. and Dumonde, D. C. (1996) Distribution of TNF $\alpha$ and its reactive vascular adhesion molecules in fibrovascular membranes of proliferative diabetic retinopathy. Br. J. Ophthalmol. 80; 168-173.

30. Lu, Y., Parkyn, L., Otterbein, L. E., Kureishi, Y., Walsh, K., Ray, A. and Ray, P. (2001) Activated Akt protects the lung from oxidant-induced injury and delays death of mice. J. Exp. Med. 193; 545-549.

31. Luo, Z., Fujio, Y., Kureishi, Y., Rudic, R. D., Daumerie, G., Fulton, D., Sessa, W. C. and Walsh, K. (2000) Acute modulation of endothelial Akt/PKB activity alters nitric oxide-dependent vasomotor activity in vivo. J. Clin. Invest. 106; 493-499.

32. Mazure, N. M., Chen, E. Y., Laderoute, K. R. and Giaccia, A. J. (1997) Induction of vascularendothelial growth factor by hypoxia is modulated by a phosphatidylinositol 3-kinase/Akt signaling pathway in Ha-ras-transformed cells through a hypoxia inducible factor-1 transcriptional element. Blood 90; 3322-3331.

33. Michell, B. J., Griffiths, J. E., Mitchelhill, K. I., RodriguezCrespo, I., Tiganis, T., Bozinovski, S., de Montellano, P. R., Kemp, B. E. and Pearson, R. B. (1999) The Akt kinase signals 
directly to endothelial nitric oxide synthase. Curr. Biol. 9; 845848 .

34. Morales-Ruiz, M., Lee, M. J., Zollner, S., Gratton, J. P., Scotland, R., Shiojima, I., Walsh, K., Hla, T. and Sessa, W. C. (2001) Sphingosine 1-phosphate activates Akt, nitric oxide production, and chemotaxis through a Gi protein/phosphoinositide 3-kinase pathway in endothelial cells. J. Biol. Chem. 276; 19672-19677.

35. Moss, S. E., Klein, R. and Klein, B. E. (1994) Ten-year incidence of visual loss in a diabetic population. Ophthalmology 101; 10611070.

36. Moss, S. E., Klein, R. and Klein, B. E. (1998) The 14-year incidence of visual loss in diabetic population. Ophthalmology $105 ; 998-1003$.

37. Murohara, T., Asahara, T., Silver, M., Bauters, C., Masuda, H., Kalka, C., Kearney, M., Chen, D., Symes, J. F., Fishman, M. C., Huang, P. L. and Isner, J. M. (1998) Nitric oxide synthase modulates angiogenesis in response to tissue ischemia. J. Clin. Invest. 101; 2567-2578

38. Nakagami, H., Morishita, R., Yamamoto, K., Taniyama, Y., Aoki, M., Matsumoto, K., Nakamura, T., Kaneda, Y., Horiuchi, M. and Ogihara, T. (2001) Mitogenic and antiapoptotic actions of hepatocyte growth factor through ERK, Stat3, and Akt in endothelial cells. Hypertension 37; 581-586.

39. Papapetropoulos, A., Garcia-Cardena, G., Madri, J. A. and Sessa, W. C. (1997) Nitric oxide production contributes to the angiogenic properties of vascular endothelial growth factor in human endothelial cells. J. Clin. Invest. 100; 3131-3139.

40. Papapetropoulos, A., Fulton, D., Mahboubi, K., Kalb, R. G., O'Connor, D. S., Li, F., Altieri, D. C. and Sessa, W. C. (2000) Angiopoietin-1 inhibits endothelial cell apoptosis via the Akt/ survivin pathway. J. Biol. Chem. 275; 9102-9105.

41. Pierce, E. A., Avery, R. L., Foley, E. D., Aiello, L. P. and Smith, L. E. (1995) Vascular endothelial growth factor/vascular permeability factor expression in a mouse model of retinal neovascularization. Proc. Natl. Acad. Sci. U S A 92; 905-909.

42. Pierce, E. A., Foley, E. D. and Smith, L. E. (1996) Regulation of vascular endothelial growth factor by oxygen in a model of retinopathy of prematurity. Arch. Ophthalmol. 114; 1219-1228.

43. Schonherr, E., Levkau, B., Schaefer, L., Kresse, H. and Walsh, K. (2001) Decorin mediated signal transduction in endothelial cells. Involvement of Akt/protein kinase B in up-regulation of p21(WAF1/CIP1) but not p27(KIP1). J. Biol. Chem. 276; 4068740692.

44. Shih, S. C., Ju, M., Liu, N. and Smith, L. E. (2003) Selective stimulation of VEGFR-1 prevents oxygen-induced retinal vascular degeneration in retinopathy of prematurity. J. Clin. Invest. $112 ; 50-57$.

45. Shiojima, I. and Walsh, K. (2002) Role of Akt signaling in vascular homeostasis and angiogenesis. Circ. Res. 90; 43-50.

46. Smith, L. E., Wesolowski, E., McLellan, A., Kostyk, S. K., D'Amato, R., Sullivan, R. and D'Amore, P. A. (1994) Oxygeninduced retinopathy in the mouse. Invest. Ophthalmol. Vis. Sci. $35 ; 101-111$.

47. Thomas, S. R., Chen, K. and Keaney, J. F. J. (2002) Hydrogen peroxide activates endothelial nitric-oxide synthase through coordinated phoshorylation and dephosphorylation via a phosphoinositide 3-kinase-dependent signaling pathway. J. Biol. Chem. 277; 6017-6024.

48. Yoshida, A., Yoshida, S., Ishibashi, T., Kuwano, M. and Inomata, H. (1999) Suppression of retinal neovascularization by the NFkappaB inhibitor pyrrolidine dithiocarbamate in mice. Invest. Ophthalmol. Vis. Sci. 40; 1624-1629.

49. Yu, W. Z., Zou, H., Li, X. X., Yan, Z. and Dong, J. Q. (2008) Effects of the phosphatidylinositol 3-kinase inhibitor in a mouse model of retinal neovascularization. Ophthalmic Res. 40; 19-25.

50. Zhan, M. and Han, Z. C. (2004) Phosphatidylinositide 3-Kinase/ AKT in radiation responses. Histol. Histopathol. 19; 915-923.

This is an open access article distributed under the Creative Commons Attribution License, which permits unrestricted use, distribution, and reproduction in any medium, provided the original work is properly cited. 